\title{
Maternal outcomes of rheumatic heart disease in pregnancy
}

\author{
Hema Priya L. ${ }^{1 *}$, Ambarish Bhandiwad ${ }^{1}$, Nagaraj Desai ${ }^{2}$, Triveni Kondareddy ${ }^{1}$
}

\author{
${ }^{1}$ Department of Obstetrics and Gynecology, JSS Medical College \& Hospital, JSS University, Mysuru Karnataka, \\ India \\ ${ }^{2}$ Department of Cardiology, JSS Medical College \& Hospital, JSS University, Mysuru Karnataka, India
}

Received: 12 January 2017

Revised: 18 January 2017

Accepted: 07 February 2017

\author{
*Correspondence: \\ Dr. Hema Priya L., \\ E-mail: drpriya_911@hotmail.com
}

Copyright: (c) the author(s), publisher and licensee Medip Academy. This is an open-access article distributed under the terms of the Creative Commons Attribution Non-Commercial License, which permits unrestricted non-commercial use, distribution, and reproduction in any medium, provided the original work is properly cited.

\begin{abstract}
Background: Preexisting cardiac disease is seen in 1-3\% of pregnancies. In developing countries, sequelae of rheumatic fever often constitute the majority of women with heart disease; whereas in developed countries, it is the congenital heart diseases. The aim of this study was to examine the changing trends and mode of care of women with Rheumatic heart disease in pregnancy over a period of five years in a tertiary care centre.

Methods: Patient records over five years were retrieved and maternal and perinatal outcomes were documented. The present study reports the outcomes of 72 women with rheumatic heart disease.

Results: The prevalence of heart disease in pregnancy in our study was $1.72 \%$. The prevalence was higher among the rural population, and in lower socio economic strata. $30 \%$ of patients were diagnosed during pregnancy. The risk of complications co - related with their functional status at the onset of pregnancy. The mode of termination of pregnancy and indications for LSCS did not vary. However, the risk of complications was greatest during labour and post-partum period. The mean birth weight was $2.7 \mathrm{~kg}$, however, $30 \%$ of term neonates were of low birth weight $(<2.5 \mathrm{~kg})$.

Conclusions: Rheumatic heart disease continues to be a major cause of cardiac disease complicating pregnancy. However, early diagnosis, appropriate management prior to pregnancy, and good functional status at the time of entering pregnancy allowed for a good maternal and neonatal outcome.
\end{abstract}

Keywords: Pregnancy, Rheumatic heart disease

\section{INTRODUCTION}

Cardiac disorders complicate approximately $1-3 \%$ of pregnancies. ${ }^{1}$ Because more women with heart disease are reaching childbearing age due to improved medical and surgical care, and desire children, the incidence and prevalence of cardiovascular disease in pregnancy is increasing. Rheumatic heart disease (RHD) continues to be a major cause of cardiac illness in developing countries. A multicentric epidemiologic study, published in 1996 by the Indian Council of Medical Research gave the national average of RHD prevalence as 6 per thousand in the age group of 5-16years. ${ }^{2}$ In India, the rheumatic heart disease contributes to approximately $69 \%$ of cardiac disorders seen in pregnancy. ${ }^{3}$ In many cases, the heart disease is diagnosed only at the time of pregnancy, as it is the first contact of the woman with a health care facility. The maternal mortality rate in women with cardiac disease is as high as $7 \%$, and morbidity rate higher than $30 \%$ during pregnancy. ${ }^{4}$

A retrospective study was conducted at JSS Hospital, which is a tertiary care teaching hospital in south India. The aim of this study was to analyze the antepartum, 
intrapartum and postpartum course of women with rheumatic heart disease; and study the factors affecting the maternal and perinatal outcomes.

\section{METHODS}

Patient records from January 2011 to December 2015 were retrieved from the Medical records department. 181 women were identified as having a cardiac disorder. The women underwent clinical examination, ECG and echocardiography. Out of the 181 women, 72 women were identified with rheumatic heart disease. There were 77 women with congenital heart disease, 23 with Mitral valve prolapse, 2 with ascending aortic aneurysm, 3 with arrhythmias, 3 with peripartum cardiomyopathy, 2 with viral myocarditis, and 3 who had a prior history of coronary artery disease. These women were excluded from the study. The patients were managed in the cardioobstetric clinic of the hospital under joint supervision of an obstetrician and cardiologist.

Baseline characteristics of the women, such as the age, parity, NYHA class at booking, gestational age at first visit, history of cardiac complications before pregnancy, cardiac medications and anticoagulation, prior history of cardiac surgery/interventions and nature of the cardiac lesion were noted. Their antenatal course, labor and delivery details, postnatal course and complications were systematically recorded. The immediate perinatal outcome was also documented. Statistical analysis was done using the SPSS software.

\section{RESULTS}

The total number of women who delivered at our institution over five years; from January 2011 to December 2015 was 10,487. The incidence of heart disease in pregnancy at our hospital was $1.72 \%$. Rheumatic heart disease was one of the most important causes of heart disease in these women. $72(39.7 \%)$ women were diagnosed to have rheumatic heart disease out of a cohort of 181 patients with cardiac disease. The demographic parameters of these patients are tabulated below:

Table 1: Demographic parameters.

\begin{tabular}{|l|l|}
\hline Mean age & $\mathbf{2 3 . 6}$ years \\
\hline 18-20 years & $22.2 \%$ \\
\hline $21-25$ years & $54.4 \%$ \\
\hline $26-30$ years & $16.7 \%$ \\
\hline $31-35$ years & $6.7 \%$ \\
\hline Residence & $66.7 \%$ \\
\hline Rural & $33.3 \%$ \\
\hline Urban & \\
\hline Occupation & $98.6 \%$ \\
\hline Housewife & \\
\hline Socio economic status & $70.8 \%$ \\
\hline Lower middle class
\end{tabular}

$54.4 \%$ of women were between 21 and 25 years of age, $22 \%$ between 18 and 20 years and none of them were above 35 years of age. $30 \%$ of patients were diagnosed with heart disease for the first time during pregnancy. The duration of heart disease ranged from 1 to 20 years; with a mean duration of 5.1 years. Table 2 shows the number of women diagnosed with RHD in various trimesters of pregnancy. They presented with a variety of symptoms ranging from shortness of breath on moderate exertion to gross edema and dyspnea at rest.

Table 2: Diagnosed in pregnancy.

\begin{tabular}{|ll|}
\hline Diagnosed in pregnancy & Percentage \\
\hline First trimester & 13.9 \\
\hline Second trimester & 5.6 \\
\hline Third trimester & 5.6 \\
\hline Post partum & 2.8 \\
\hline
\end{tabular}

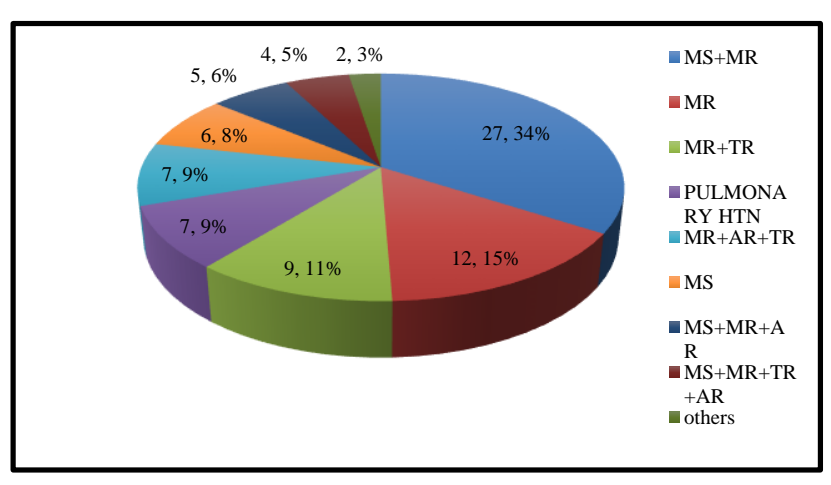

Figure 1: Type of cardiac lesion.

Majority (57\%) of the women had mitral valve disease, with mitral regurgitation (MR) being more common than stenosis. $31.9 \%$ women had mild mitral stenosis. Moderate and severe stenosis was seen in $19.4 \%$ and $14 \%$ patients respectively. Mild MR was seen in $34.7 \%$ patients, $19 \%$ had moderate MR and $16 \%$ had severe mitral regurgitation. The aortic valve was less commonly involved. Isolated aortic stenosis was seen in only $2.8 \%$ of women. Aortic stenosis along with mitral valve disease was present in $9.8 \%$ of patients. $15.5 \%$ of patients had associated aortic regurgitation. Pulmonary hypertension was seen as a complicating factor in $9 \%$ of patients.

$79 \%$ of women remained NYHA Class 1 throughout pregnancy and up to 48 hours post-partum. However, worsening of NYHA status was seen in 4 (5.5\%) of patients in the third trimester. Four patients went into cardiac failure, and 6 developed atrial fibrillations. It was seen that women who underwent surgical correction of the cardiac lesion prior to pregnancy had a good outcome, and did not have worsening of cardiac status. $6.9 \%$ of women had a balloon mitral valvotomy, 5.5\% had a mitral mechanical valve replacement and $1.3 \%$ had a mitral valve repair prior to pregnancy. Three patients $(4.1 \%)$ underwent percutaneous mitral commissurotomy (PTMC) in the second trimester of pregnancy. All of them had severe mitral stenosis and were in NYHA class 
II/III at time of intervention. All of them had a significant improvement after the procedure, and an uneventful delivery.

$62.5 \%$ of women were on penicillin prophylaxis and it was continued throughout pregnancy. Infective endocarditis prophylaxis was given at time of delivery to all patients. $9.7 \%$ of women were on anticoagulants before, and during pregnancy. They were switched from oral to low molecular weight heparin in the first trimester and then again at $36-37$ weeks. Oral anticoagulants were continued in the second and most of the third trimester, and also post-partum. $8.3 \%$ of women required $\beta$ blockers to control the heart rate, and $5.5 \%$ required anti failure measures during pregnancy or in the immediate post-partum period. However, no fetal anomalies including warfarin embryopathy were seen due to maternal drug intake.

Regarding the obstetric outcome, $51.4 \%$ women were primigravidas. $27.7 \%$ were in their second pregnancy. Higher order pregnancy (>G3) were seen in $5.4 \%$ of women. In this cohort of patients, various obstetric and medical complications were seen, which are tabulated below.

Table 3: Obstertic and medical comorbidity.

\begin{tabular}{|ll|}
\hline Obstetric and medical comorbidity & Percentage \\
\hline Gestational hypertension & 2.7 \\
\hline Pre-eclampsia & 2.7 \\
\hline Hypothyroid & 2.7 \\
\hline Moderate to severe anaemia & 4.1 \\
\hline Gestational diabetes mellitus & 1.3 \\
\hline Inevitable abortion & 2.7 \\
\hline PPROM & 1.3 \\
\hline
\end{tabular}

$80.6 \%$ of women had a full-term delivery. $13.9 \%$ were late pre-term births, and $2.8 \%$ had an early pre-term delivery at $<34$ weeks. The details regarding the mode of delivery are shown in Figure 2.

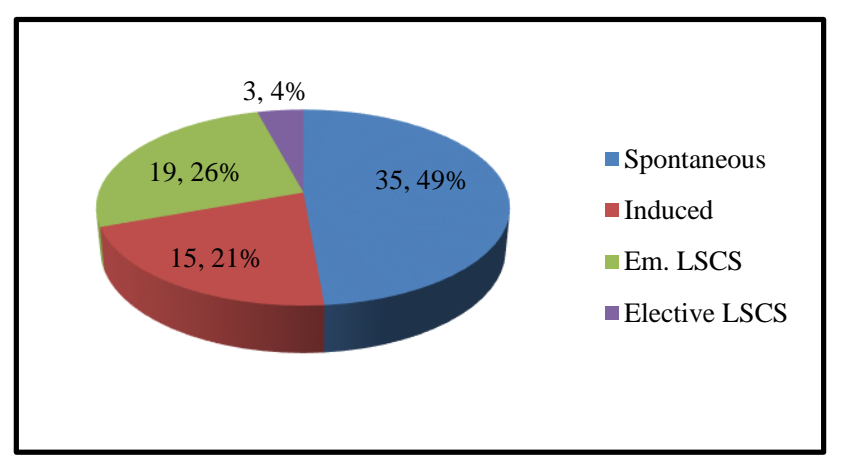

Figure 2: Mode of delivery.

Labor was induced in 15 patients, the indication being completion of 40 weeks of gestation in $80 \%$ of patients. Other indications for induction of labor were Premature rupture of membranes and intra uterine fetal demise. Of the $70 \%$ patients who delivered vaginally, 9 patients $(18 \%)$ required instrumental delivery. $12 \%$ were outlet forceps and $6 \%$ vacuum extractions respectively. The indication for instrumentation in all patients was to cut short the second stage of labor, and prevent excessive bearing down efforts by the mother.

Lower segment Cesarean section (LSCS) was done in $30 \%$ of women. 3 patients underwent Elective LSCS, the indication being previous LSCS. The various indications for Emergency LSCS are tabulated below. Spinal anesthesia was given in $95 \%$ of cases and General anesthesia in $5 \%$.

Table 4: Indication for emergency LSCS.

\begin{tabular}{|ll|}
\hline Indication for emergency LSCS & Percentage \\
\hline Malpresentation & 2.7 \\
\hline Severe oligoamnios & 5.5 \\
\hline Previous LSCS & 2.7 \\
\hline Contracted pelvis & 4.1 \\
\hline Failed induction & 1.3 \\
\hline Cephalo pelvic disproportion & 2.7 \\
\hline Non-progress of labor & 1.3 \\
\hline Fetal bradycardia & 1.3 \\
\hline Total & 4.1 \\
\hline
\end{tabular}

The birth weight of the neonates ranged from $1.2 \mathrm{~kg}$ to 4 $\mathrm{kg}$, with a mean of $2.7 \mathrm{~kg}$. $60 \%$ of neonates were appropriate for gestational age infants, weighing between 2.5-3.5 kg. Almost 30\% of the newborns were of low birth weight $(<2.5 \mathrm{~kg})$ after excluding pre-term neonates. $4.2 \%$ of babies were large for gestational age $(>3.5 \mathrm{~kg})$. The detailed neonatal follow up was not available after discharge from hospital. However, there were no major morbidities and no mortality.

A total of $5.6 \%$ of women had complications in the postpartum period. One patient required packed cell transfusion due to severe anemia. Three patients required post-partum Intensive care due to congestive cardiac failure. All of them had severe mitral stenosis with severe mitral regurgitation. They were managed with diuretics, oxygen and $\beta$ blockers. One patient required inotropic support. All of them recovered well, and were discharged after their condition was stable. There was no maternal mortality despite three near miss events.

\section{DISCUSSION}

Heart disease of rheumatic origin is a major complicating factor in pregnancy in developing countries. In our study, the prevalence of heart disease in pregnancy was $1.72 \%$; of which $39.7 \%$ women were diagnosed with rheumatic heart disease. Earlier studies of the Indian population showed a prevalence ranging from $88 \%$ to $68 \%$. $^{5,6}$ This showed a steady decrease in the incidence of rheumatic heart disease complicating pregnancy in India, which is the result of improved awareness and access to 
healthcare. This decreasing trend has also been seen in our study.

The mitral valve was the most commonly involved. Isolated mitral valve lesions; both stenosis and regurgitation accounted for $57 \%$ of our subjects. This was similar to the observations of Sheela et al. ${ }^{7}$ The outcome of pregnancy was determined by the maternal functional status in the first trimester of pregnancy. NYHA class III and IV strongly predicted an adverse maternal outcome. There was no maternal mortality encountered in our study; however postpartum ICU admissions were seen in 4 women who had a poor functional status. Sawhney et al reported a maternal mortality rate of $2 \%$ in women with cardiac disease. They studied 486 women over a period of 13 years. Ten deaths were seen, of which 8 women $(80 \%)$ were NYHA class III or IV. ${ }^{8}$

$15 \%$ of present patients underwent palliative or valve replacement surgery prior to pregnancy. All of them tolerated pregnancy well. The European task force on the Management of Cardiovascular Diseases in Pregnancy also recommends surgical correction of the valve defect prior to pregnancy.16 However, the longer the interval between valvotomy and pregnancy, the higher was the chance of cardiac failure. Several studies have shown that conservative cardiac surgery was safe in pregnancy, especially in the second and early third trimester. The most commonly done surgeries during pregnancy has been percutaneous balloon commissurotomy. ${ }^{9-11}$

The greatest risk for an adverse cardiac event occurring was during labor and in the immediate post-partum period. Hence delivery was best carried out at a tertiary center with intensive care facilities and under the joint supervision of an obstetrician and cardiologist. ${ }^{12}$ Antibiotic prophylaxis against infective endocarditis was recommended. ${ }^{8}$ Assisted vaginal delivery with instruments was preferred, in order to prevent maternal strain and exhaustion. In present study, the rate of instrumental delivery was $18 \%$, as majority of the patients had a short second stage of labour, and delivered without assistance. Epidural analgesia was recommended for all patients undergoing vaginal delivery, as it prevented tachycardia without significant hemodynamic changes. This avoided the sudden increase in blood flow across the mitral valve and prevented sudden rise in left atrial pressure. ${ }^{17}$ Cesarean section for obstetric indications was done in $30 \%$ of patients in our study with good outcomes. Various other studies have reported an incidence of $16-20 \% .^{13}$ The JCS joint working group recommended cesarean section only for patients with cardiac dysfunction, patient at risk of hemodynamic instability, pulmonary hypertension, uncontrolled arrhythmia, mechanical valve prosthesis, and patients

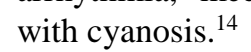

Regional anesthesia, either epidural or spinal was safe in cardiac patients presenting for caesarean section. Spinal anesthesia was safely used in $95 \%$ of patients who underwent LSCS. Other studies have reported caesarean sections with cardiac disease under spinal anesthesia with a success rate of $99 \% .^{18}$

$50 \%$ of babies in our study had a birth weight ranging from $2.5-3.5 \mathrm{~kg}$, which is considered appropriate for the term neonate. However almost $30 \%$ of the term new born were of low birth weight $(<2.5 \mathrm{~kg})$. A similar finding was reported by Soma Pillay et al.15 Small for gestational age babies were seen in $18.2 \%$ of women with cardiac disease as reported by Sawhey et al. ${ }^{8}$ This suggests that cardiac disease itself could be one of the risk factors for low birth weight.

Although the incidence of rheumatic heart disease has decreased, it is still an important cause of maternal and perinatal morbidity. Educating prospective parents before the pregnancy and screening for heart diseases is the way to go to reduce the burden further. This may pick up women with cardiac conditions which are amenable to satisfactory palliations like percutaneous valvuloplasty and corrective surgeries.

\section{CONCLUSION}

The rheumatic heart disease continues to contribute to the maternal morbidity. Although maternal mortality has reduced, near miss cases, or those requiring intensive care are still high. The multidisciplinary management reduces the adverse events resulting in satisfactory maternal and fetal outcomes.

Funding: No funding sources

Conflict of interest: None declared

Ethical approval: The study was approved by the Institutional Ethics Committee

\section{REFERENCES}

1. Nanna M, Stergiopoulos K. Pregnancy Complicated by Valvular Heart Disease: An Update. J Am Heart Assoc. 2014;3(3):e000712.

2. Thakur JS, Negi P, Ahluwalia S, Vaidya K. Epidemiological survey of rheumatic heart disease among school children in the Shimla Hills of northern India: prevalence and risk factors. J Epidemiol Community Health. 1996;50(1):62-7.

3. Konar H, Chaudhuri S. Pregnancy Complicated by Maternal Heart Disease: A Review of 281 Women. J Obstet Gynaecol India. 2012;62(3):301-6.

4. Pushpalatha K. Cardiac diseases in pregnancy- A review, JIMSA. 2010;23(4):269-74.

5. Bhatla N, Lal S, Behera G, Kriplani A, Mittal S, Agarwal N. Cardiac disease in pregnancy. Int J Gynaecol Obstet. 2003;82:153-9.

6. Doshi HU, Oza HV, Tekani H, Modi K. Cardiac disease in pregnancy-maternal and perinatal outcome. J Indian Med Assoc. 2010;108:278-80.

7. Sheela CN, ShashikalaKaranth, Patil CB. Maternal cardiac complications in women with cardiac disease 
in pregnancy. Int $\mathrm{J}$ Pharm Biomed Res. 2011;2(4):261-5.

8. Sawhney H, Aggarwal N, Suri V, Vasishta K, Sharma Y, Grover A. Maternal and perinatal outcome in rheumatic heart disease. Int J Gynaecol Obstet. 2003;80;9-14.

9. Aggarwal N, Suri V, Goyal A, Malhotra S, Manoj R, Dhaliwal RS. Closed Mitral Valvotomy in Pregnancy and Labor. Int J Gynaecol Obstet. 2005;88:118-21.

10. Fawzy ME. Mitral balloon valvuloplasty. Catheter Cardiovasc Interv. 2007;69:313-21.

11. Hameed AB, Mehra A, Rahimtoola SH. The role of catheter balloon commissurotomy for severe mitral stenosis in pregnancy. Obstet Gynecol. 2009;114:1336-40.

12. Bangal B, Singh K, Shinde K. Clinical Study of Heart Disease Complicating Pregnancy. IOSR. 2012;2(4):25-8.

13. Nqayana T, Moodley J, Naidoo DP. Cardiac disease in pregnancy. Cardiovasc J Afr. 2008;19:145-51.

14. JCS Joint Working Group. Guidelines for indication and management of pregnancy and delivery in women with heart disease (JCS 2010): digest version. Circ J. 2012;76:240-60.

15. Soma-pillay P, MacDonald AP, Mathivha TM, Bakker JL, Mackintosh MO. Cardiac disease in pregnancy: a 4-year audit at Pretoria Academic Hospital. S Afr Med J. 2008;98:553-6.

16. Regitz-Zagrosek V, Blomstrom Lundqvist C, Borghi C, Cifkova R, Ferreira R, Foidart JM, et al; European Society of Gynecology (ESG); Association for European Paediatric Cardiology (AEPC); German Society for Gender Medicine (DGesGM). ESC Guidelines on the management of cardiovascular diseases during pregnancy: the Task Force on the Management of Cardiovascular Diseases during Pregnancy of the European Society of Cardiology (ESC). Eur Heart J. 2011;32(24):3147-97.

17. Sharma SK, Gambling DR, Gajraj NM, Truong C, Sidawi EJ. Anesthetic management of a parturient with mixed mitral valve disease and uncontrolled atrial fibrillation. Int J Obstet Anesth. 1994;3:157-62.

18. Dresner M, Pinder A. Anaesthesia for caesarean section in women with complex cardiac disease: 34 cases using the Braun Spinocath spinal catheter. Int $\mathrm{J}$ Obstet Anesth. 2009;18:131-6.

Cite this article as: Priya HL, Bhandiwad A, Desai N, Kondareddy T. Maternal outcomes of rheumatic heart disease in pregnancy. Int $\mathrm{J}$ Reprod Contracept Obstet Gynecol 2017;6:802-6. 